\title{
PENGARUH MODEL PEMBELAJARAN KREATIF PRODUKTIF TERINTEGRASI DENGAN BLOG DAN FACEBOOK TERHADAP PRESTASI DAN MOTIVASI BELAJAR IPA SISWA KELAS VIII SMP
}

\author{
Ida Rianawaty \\ SMP Negeri 5 Kota Magelang \\ idarianawaty@gmail.com
}

\begin{abstract}
Abstrak
Penelitian ini bertujuan untuk: (1) untuk mengetahui pengaruh model pembelajaran kreatif produktif yang terintegrasi dengan Blog dan Facebook terhadap prestasi belajar IPA siswa kelas VIII SMP Negeri 5 Magelang. (2) untuk mengetahui pengaruh model pembelajaran kreatif produktif yang terintegrasi dengan blog dan Facebook efektif terhadap motivasi belajar IPA siswa kelas VIII SMP Negeri 5 Magelang.

Jenis penelitian ini adalah penelitian eksperimen dengan desain Quasi eksperimen dan model Nonequivalent control group. Sampel dalam penelitian ini adalah siswa kelas VIII C yang berjumlah 26 siswa sebagai kelas perlakuan dengan menerapkan model pembelajaran kreatif produktif yang terintegrasi dengan blog dan Facebook, dan kelas VIII A yang berjumlah 26 siswa dengan menerapkan model pembelajaran kreatif produktif yang tidak terintegrasi dengan Blog dan Facebook.

Hasil penelitian menunjukkan bahwa: Pengaruh model pembelajaran kreatif produktif yang terintegrasi dengan blog dan Facebook terhadap prestasi siswa kelas VIII C SMP N 5 Kota Magelang, ketuntasan yang dicapai dengan KKM 75 adalah 100\% dengan rata-rata pre test 45,92 menjadi 82,50. Sedangkan untuk kelas VIII A (kelas kontrol), ketuntasan kelas yang dicapai 96,15 \%, dengan rata-rata pre test 45,21 menjadi 80,83. Perbandingan hasil rerata posttest kedua kelas tersebut sebesar 1,67. Tetapi hasil uji t dengan SPSS diperoleh nilai $\mathrm{p}$ sebesar 0,262 pada taraf signifikansi 5\%. Dengan demikian disimpulkan bahwa tidak terdapat perbedaan yang signifikan terhadap rata-rata hasil belajar siswa kelas VIII yang menggunakan model pembelajaran kreatif produktif terintegrasi dengan blog dan Facebook dengan kelas kontrol. Sedangkan pengaruh model pembelajaran kreatif produktif yang terintegrasi dengan blog dan Facebook efektif meningkatkan motivasi belajar IPA siswa kelas VIII C SMP N 5 Kota Magelang yaitu dari 41,83\% menjadi 70,76 \% setelah proses pembelajaran (termasuk kategori tinggi). Hal ini didukung oleh hasil wawancara kepada siswa bahwa proses pembelajaran menarik, dan siswa lebih fleksibel untuk berkomunikasi dari mana saja dengan guru melalui Facebook dan termotivasi untuk belajar. Sedangkan kelas VIII A (kelas kontrol) motivasi belajar sebelum proses pembelajaran 42,31\% meningkat menjadi 61,06 \%, termasuk kategori sedang. Dengan demikian dapat disimpulkan bahwa model pembelajaran kreatif produktif yang terintegrasi dengan blog dan Facebook terdapat perbedaan signifikan terhadap peningkatan motivasi siswa kelas VIII C SMP N 5 Kota Magelang.
\end{abstract}

Kata kunci: kreatif produktif, belajar IPA, blog dan facebook 


\title{
THE INFLUENCE OF PRODUCTIVE CREATIVE LEARNING MODEL INTEGRATED WITH THE BLOG AND FACEBOOK TO ACHIEVE AND MOTIVATE TO LEARNING SCIENCE FOR EIGHT GRADE OF JUNIOR HIGH SCHOOL
}

\author{
Ida Rianawaty \\ SMP Negeri 5 Kota Magelang \\ idarianawaty@gmail.com
}

\begin{abstract}
This study aims to: (1) to determine the influence of productive creative learning model integrated with the blog and Facebook to science learning achievement IPA eighth grade students of SMP Negeri 5 Magelang, (2) to determine the influence of productive creative learning model integrated with the blog and Facebook on motivation to learn science eighth grade students of SMP Negeri 5 Magelang.

This research is a research experimental design with quasi experimental and Nonequivalent control group models. The samples in this study were students of class VIII C and VIII A. The researcher applied creative productive learning model integrated with Facebook and blogs for VIIIC, In the other hand, VIII A did not use this treatment.

The results showed that: the influence of creative productive learning model integrated with the blog and Facebook for eighth graders achievement of SMP Negeri 5 Magelang, completeness is achieved by KKM 75 was $100 \%$ with an average pre-test 45.92 to 82.50. As for the class VIII A (control class), the class achieved mastery $96.15 \%$, with an average pre-test 45.21 to 80.83 . Comparison the results of these two classes post test mean of 1.67. But the results of the t test $P$ values obtained with SPSS (probability) of 0.262 at a significance level of $5 \%$. Therefore there was no significant difference in the average class VIII student learning outcomes using creative productive learning model integrated with the blog and Facebook with the control class. While the influence of creative productive learning model integrated with the blog and Facebook effectively improve students' motivation to learn science in class VIII C SMP N 5 Magelang ie from $41.83 \%$ to $70.76 \%$ after the learning process (high category). This is supported by the results of the interview to the students that the learning process interesting, and students more practical to communicate from anywhere with the teacher through Facebook and motivated to learn. While class VIII A (grade control) the motivation to learn before learning is $42.31 \%$ increase to $61.06 \%$, including the medium category. It can be concluded that a productive creative learning model integrated with the blog and Facebook there is a significant difference to the increased motivation of students of class VIII C SMP N 5 Magelang.
\end{abstract}

Keywords: creative productive, learn science, blog and Facebook 


\section{Pendahuluan}

Abad 21 merupakan abad informasi dan komunikasi, yang ditandai dengan perkembangan pesat pada teknologi informasi dan komunikasi. Tantangan pendidikan abad 21 adalah membangun masyarakat berpengetahuan (knowledgebased society) yang menguasai ICT (information comunication technology), dan media literacy skills, kemampuan berpikir kritis, kemauan memecahkan masalah, dan kemampuan berkolaburasi.

Sekolah sebagai institusi pencetak generasi yang hidup dimasa mendatang harus mempunyai kepedulian terhadap perkembangan yang terjadi. Jika tidak, maka anak-anak yang kita didik akan tertinggal dengan perkembangan zaman. Guru pada abad ini dan abad selanjutnya ditantang untuk melakukan akselerasi terhadap perkembangan informasi dan komunikasi. Pembelajaran di kelas dan pengelolaan kelas, pada abad ini harus disesuaikan dengan standar kemajuan ICT. Proses pembelajaran yang berbasis ICT menuntut peran guru yang semakin besar karena harus bisa menciptakan pembelajaran yang menarik. Guru harus mampu mengarahkan dan memfasilitasi siswa dalam mengembangkan pengetahuan dan skillnya.

Pendidikan merupakan proses untuk mengembangkan seluruh aspek yang ada pada diri individu, agar seluruh potensi yang dimilikinya dapat berkembang secara utuh. Sehingga harus diperkuat pandangan bahwa pendidikan melahirkan the whole person, karena manusia dibekali Tuhan dengan kekuatan intelektual, kekuatan tubuh dan kekuatan moral yang semuanya harus dikembangkan secara terpadu dan harmonis agar dapat menjadi individu yang tidak saja berguna bagi diri pribadi dan keluarga tetapi juga bermanfaat bagi masyarakat dan bangsanya (Zamroni, 2011, pp.93-94).

Hal senada juga diungkapkan Thomas Armstrong (2006, p.39) tujuan pendidikan adalah untuk mendukung, mendorong dan memfasilitasi perkembangan siswa sebagai manusia yang utuh (a whole human being). Praktik pendidikan di sekolah untuk membentuk manusia yang utuh (a whole human being), sesuai tujuan pendidikan nasional kita yang tertuang dalam UU No. 20 tahun 2003 masih jauh dari harapan. Guru di sekolah seolah hanya melihat standar kompetensi dan kompetensi dasar masing-masing mata pelajaran yang mereka ampu, tanpa memperdulikan visi-misi sekolah, tujuan masing-masing jenjang pendidikan menurut kurikulum dan tujuan pendidikan nasional.

SMP Negeri 5 kota Magelang merupakan salah satu dari 13 SMP Negeri di kota Magelang yang statusnya SSN (Sekolah Standar Nasional). Sekolah tersebut menduduki peringkat 10 berdasarkan ratarata hasil UN (Ujian Nasional) tahun 2013 dari 21 SMP Negeri dan Swasta di Kota Magelang. Fasilitas pendukung ICT untuk proses pembelajaran seperti tersedianya koneksi internet di area sekolah, LCD (Liquid Crystal Display) terpasang di setiap kelas dan laboratorium, dan hampir setiap guru memiliki laptop. Tetapi proses pembelajaran di sekolah ini dikatakan sedang meniti jalan untuk membentuk manusia yang utuh (a whole human being), sesuai harapan tujuan pendidikan nasional kita.

Proses pembelajaran di SMP N 5 Magelang yang memiliki visi "Berprestasi dan Berakhlak Mulia" ini masih didominasi model pembelajaran ceramah (ekspositori). Proses pembelajaran yang diterapkan di kelas masih berpusat pada guru (teacher centtre), meskipun ada juga beberapa diantara guru telah menerapkan proses pembelajaran yang student centre (berpusat pada siswa) dan berbasis ICT.

Proses pembelajaran yang berpusat pada guru (teacher centre) tidak menarik bagi siswa, hal ini menyebabkan konsentrasi belajar siswa kurang optimal ketika proses pembelajaran berlangsung. Sehingga dibutuhkan model pembelajaran yang lebih bervariasi dan menumbuhkan motivasi siswa untuk belajar. Konsentrasi belajar siswa yang kurang optimal ketika proses pembelajaran berlangsung, berdam- 
pak pada rendahnya motivasi dan penyerapan materi pembelajaran yang ditunjukan oleh prosentasi ketuntasan belajar klasikal yang hanya $68 \%$ setiap dilakukan tes ulangan harian, ulangan tengah semester dan Ulangan semester.

Kurang optimalnya konsentrasi belajar siswa ini menjadi kendala bagi siswa untuk menyimpan materi pelajaran tersebut dalam ingatan/memori/kesan siswa. Proses pembelajaran IPA yang bermakna dan berkualitas adalah yang mampu memberikan pengalaman belajar secara langsung melalui penggunaan dan pengembangan ketrampilan proses dan sikap ilmiah. Dalam rangka memberikan pengalaman belajar langsung tersebut, seorang guru diharapkan dapat memanfaatkan ICT untuk memperjelas konsep IPA yang abstrak menjadi lebih kongkrit dengan menggunakan multimedia seperti komputer, internet, video dan lain-lain yang dikembangkan agar pembelajaran IPA menjadi lebih berkesan dan bermakna.

Guru dituntut untuk pandai meramu berbagai model, metode, strategi, dan taktik pembelajaran yang memanfaatkan ICT, seperti kapan menggunakan chat, e-mail, blog, elearning, presentasi dengan slide powerpoint, simulasi, dan lain-lain. Kehadiran teknologi Internet sudah banyak membantu dan memberikan peluang bagi dunia pendidikan untuk meningkatkan kreativitas guru dalam membangun dan mengembangkan media pembelajaran. Model pembelajaran yang diterapkan guru di kelas akan lebih menarik motivasi siswa jika didukung oleh media pembelajaran, sehingga materi pelajaran mudah dipahami oleh peserta didik, dan dapat membuat suasana belajar lebih menyenangkan.

Blog dan Facebook dapat digunakan untuk media pembelajaran yang menyediakan materi-materi pelajaran sekolah dan dapat diunduh oleh peserta didik. Tugastugas sekolah disertai materi-materi penjelasnya dapat disediakan di blog. Sehingga ketika peserta didik mengalami kesulitan dalam mengerjakan tugasnya, mereka dapat mencari langkah pengerjaannya di blog gurunya. Sedangkan Facebook digunakan untuk melengkapi blog, resensi-resensi singkat dapat diposting di status Facebook yang dilengkapi alamat blog-nya. Salah satu kelebihan Facebook dibandingkan blog adalah lebih interaktif dan mudah diakses di media mobile (HP). Media pembelajaran blog itu lebih lengkap, sedangkan media pembelajaran Facebook lebih interaktif.

Media online yang diuraikan diatas dapat lebih meningkatkan komunikasi guru dengan siswanya dimana saja dan kapan saja. sehingga komunikasinya tdk hanya terbatas di ruang kelas saja. Oleh karena itu penulis mencoba mengetahui pengaruh model pembelajaran kreatif produktif yang terintegrasi dengan blog dan Facebook terhadap prestasi dan motivasi belajar IPA siswa kelas VIII SMP.

Dari uraian latar belakang di atas, maka dapat dirumuskan permasalahan sebagai berikut: (1) Apakah model pembelajaran kreatif produktif yang terintegrasi dengan blog dan Facebook lebih efektif meningkatkan prestasi belajar IPA siswa kelas VIII SMP Negeri 5 Magelang dibandingkan dengan model pembelajaran kreatif produktif yang tidak terintegrasi dengan blog dan Facebook?; (2) Apakah model pembelajaran kreatif produktif yang terintegrasi dengan blog dan Facebook lebih efektif meningkatkan motivasi belajar IPA siswa kelas VIII SMP Negeri 5 Magelang dibandingkan dengan model pembelajaran kreatif produktif yang tidak terintegrasi dengan blog dan Facebook?

Tujuan yang hendak dicapai dalam penelitian ini adalah: (1) untuk mengetahui pengaruh model pembelajaran kreatif produktif yang terintegrasi dengan blog dan Facebook terhadap prestasi belajar IPA siswa kelas VIII SMP Negeri 5 Magelang; (2) untuk mengetahui pengaruh model pembelajaran kreatif produktif yang terintegrasi dengan blog dan Facebook efektif terhadap motivasi belajar IPA siswa kelas VIII SMP Negeri 5 Magelang.

Manfaat dari penelitian ini terdiri dari dua bagian, yaitu manfaat teoritis dan praktis.

Manfaat teoritis yaitu: (1) memberikan kontribusi terhadap pengembangan 
pendidikan di Indonesia, sehingga kajian penelitian ini merupakan bagian dari rujukan; (2) memperkaya hasil penelitian yang telah ada dan memberi inspirasi untuk menerapkan model pembelajaran kreatif produktif yang terintegrasi dengan blog dan Facebook untuk meningkatkan prestasi dan motivasi belajar siswa.

Manfaat Praktis yaitu: (1) penelitian ini bisa digunakan khususnya oleh guru, pengembang kurikulum, sekolah, dan Dinas Pendidikan, sebagai alternatif model pembelajaran yang dapat meningkatkan prestasi dan motivasi belajar siswa; (2) bagi siswa memberikan pengalaman belajar yang menarik dan menyenangkan dengan memperhatikan modalitas belajar siswa, untuk meningkatkan prestasi dan motivasi belajar IPA.

\section{Metode Penelitian}

Metode yang digunakan dalam penelitian ini adalah penelitian eksperimen (experimental research). Penelitian eksperimen ini dilakukan dengan memilih desain Quasi eksperimen dengan model Nonequivalent control group. pada desain ini kelompok eksperimen maupun kelompok kontrol tidak dipilih secara random. Dalam desain ini, baik kelompok eksperimental maupun kelompok kontrol dibandingkan. Dua kelompok yang ada diberi pretes, kemudian diberikan perlakuan, dan terakhir diberikan postes.

Penetapan kelas kontrol dan kelas perlakuan dilakukan dengan memilih kelas yang kemampuan siswanya terdistribusi normal serta melihat nilai tertinggi, nilai terendah, dan rata-rata hasil ulangan harian pertama untuk mata pelajaran IPA. Diperoleh 2 kelas dari 7 kelas paralel yang pencapaian nilai rata-rata kelas ulangan harian pertamanya 79,8 untuk kelas VIII A dan 80,01 untuk kelas VIII C. Kemudian ke 2 kelas tersebut diundi mana yang akan ditetapkan sebagai kelas kontrol. Terpilih kelas VIII A sebagai kelas control dan VIII C sebagai kelas perlakuan.

\section{Hipotesis Penelitian}

$\mathbf{H}_{01}$ : Tidak terdapat perbedaan yang signifikan terhadap rata-rata prestasi belajar siswa Kelas VIII yang menggunakan model pembelajaran kreatif produktif terintegrasi dengan blog dan Facebook dibandingkan dengan kelas kontrol.

$\mathbf{H}_{\mathbf{0 2}}$ : Tidak terdapat perbedaan yang signifikan terhadap rata-rata motivasi belajar siswa kelas VIII yang menggunakan model pembelajaran kreatif produktif terintegrasi dengan blog dan Facebook dibandingkan dengan kelas kontrol.

$\mathbf{H}_{11}$ : Terdapat perbedaan yang signifikan terhadap rata-rata prestasi belajar siswa kelas VIII yang menggunakan model pembelajaran kreatif produktif terintegrasi dengan blog dan Facebook dibandingkan dengan kelas kontrol.

$\mathbf{H}_{12}$ : Terdapat perbedaan yang signifikan terhadap rata-rata motivasi belajar siswa kelas VIII yang menggunakan model pembelajaran kreatif produktif terintegrasi dengan blog dan Facebook dibandingkan dengan kelas kontrol.

Teknik pengumpulan data dilakukan dengan observasi, wawancara, dan kuesioner. Data hasil pretest dan posttest yang diperoleh dari hasil evaluasi sumatif akan dianalisis dengan program SPSS untuk mengetahui apakah ada perbedaan antara proses pembelajaran dengan menggunakan bahan ajar sains bilingual berbasis web. dengan proses pembelajaran sains dengan menggunakan bahan ajar cetak. Sebelum dilakukan uji t dengan SPSS, data yang diperoleh dilakukan uji normalitas dan uji homogenitas terlebih dahulu. Uji normalitas dilakukan untuk mengetahui apakah data berdistribusi normal atau tidak.

Selanjutnya untuk menetapkan tingkat keefektifan proses pembelajaran dengan model pembelajaran kreatif produktif terintegrasi dengan blog dan Facebook (Kelas perlakuan) di kelas VIII C dengan kelas VIII A (kelas control) terhadap 
prestasi siswa, dilakukan uji $t$ dengan SPSS. Sedangkan untuk mengetahui tingkat keefektifan proses pembelajaran dengan model pembelajaran kreatif produktif terintegrasi dengan blog dan Facebook (Kelas perlakuan) di kelas VIII C dengan kelas VIII A (kelas kontrol), dilakukan dengan klasifikasi hasil persentase Skor Motivasi Belajar Siswa berdasarkan tabel 1.

Tabel 1. Klasifikasi Hasil Persentase Skor Motivasi Belajar Siswa

\begin{tabular}{cc}
\hline $\begin{array}{c}\text { Persentase skor yang } \\
\text { diperoleh }\end{array}$ & Kategori \\
\hline $66,68 \% \leq X \leq 100 \%$ & Tinggi \\
$33,34 \% \leq X \leq 66,67 \%$ & Sedang \\
$0 \% \leq X \leq 33,33 \%$ & Rendah \\
\hline
\end{tabular}

\section{Hasil Penelitian}

Pengaruh Perlakuan terhadap Prestasi Belajar IPA

Setelah dilakukan proses pembelajaran selama 5 X 40 menit sebanyak 3 kali pertemuan, siswa diminta mengerjakan soal post test (soal sama dengan pre tes). Data penelitian menunjukkan bahwa ketuntasan yang dicapai kelas perlakuan (VIII C) setelah di akhir penelitian dengan KKM 75 adalah 100\%, sedangkan kelas perlakuan ketuntasan kelas yang dicapai 96,15\% karena ada satu siswa yang tidak tuntas.

Perubahan nilai rata-rata pre test 45,92 menjadi 82,50 pada kelas perlakuan. Sedangkan untuk kelas kontrol rata-rata pre test 45,21 menjadi 80,83. Perbandingan hasil rerata post test kedua kelas tersebut sebesar 1,67 antara kelas kontrol dengan kelas perlakuan dapat dilihat pada Gambar 1.

Dari hasil penelitian antara kelas kontrol dan kelas perlakuan, perubahan nilai rata-rata kelas hanya selisih 1,67. dan dilihat dari jumlah siswa yang tuntas terdapat perbedaan ketuntasan 3,85\%. Tetapi hasil uji $t$ dengan SPSS diperoleh nilai $\mathrm{P}$ (probabilitas) sebesar 0,262 pada taraf signifikansi $5 \%$.

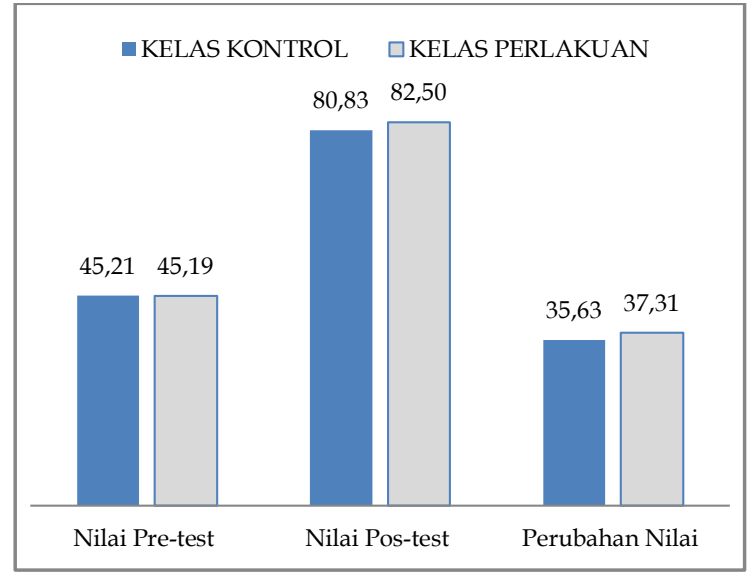

Gambar 1. Perbandingan Nilai Pre tes dan Post Tes Serta Perubahannya

Pengaruh Perlakuan Terhadap Motivasi Belajar IPA

Ketertarikan siswa ketika mengikuti proses pembelajaran merupakan respon yang sangat baik untuk meningkatkan hasil belajar siswa. Karena keberhasilan sebuah proses pembelajaran dilihat dari respon siswa dan hasil evaluasi dngan post tes. Proses pembelajaran yang berkualitas dipengaruhi oleh banyak faktor salah satu diantaranya adalah pemilihan model yang tepat dalam mendukung proses pembelajaran dan sesuai dengan karakteristik siswa, serta tersedianya sarana prasarana di sekolah. Sebagai guru, menciptakan ketertarikan siswa terhadap sajian-sajian pembelajaran merupakan suatu keharusan, supaya siswa termotivasi dalam belajar. Kreativitas seorang guru diuji, bagaimana cara menyajikan materi ajar yang menarik dan menyenangkan bagi siswa, sehingga dapat meningkatkan hasil belajarnya.

Pengaruh model pembelajaran kreatif produktif yang terintegrasi dengan $b \log$ dan Facebook efektif meningkatkan motivasi belajar IPA siswa kelas VIII C SMP N 5 Kota Magelang yaitu dari $41,83 \%$ menjadi $70,76 \%$ setelah proses pembelajaran (termasuk kategori tinggi). Hal ini didukung data kualitatif dari hasil wawancara kepada siswa yang menyatakan bahwa proses pembelajaran lebih menarik dan menyenangkan, dan siswa lebih fleksibel untuk berkomunikasi dari mana saja dengan guru melalui Facebook dan termotivasi 
untuk belajar. Sedangkan kelas VIII A (kelas kontrol) motivasi belajar sebelum proses pembelajaran $42,31 \%$ meningkat menjadi $61,06 \%$, termasuk kategori sedang. Sehingga dapat disimpulkan bahwa model pembelajaran kreatif produktif yang terintegrasi dengan blog dan Facebook terdapat perbedaan signifikan terhadap peningkatan motivasi siswa kelas VIII C SMP N 5 Kota Magelang. Perbedaan motivasi belajar IPA sebelum dan sesudah penelitian dalam bentuk grafik dapat dilihat pada Gambar 2.

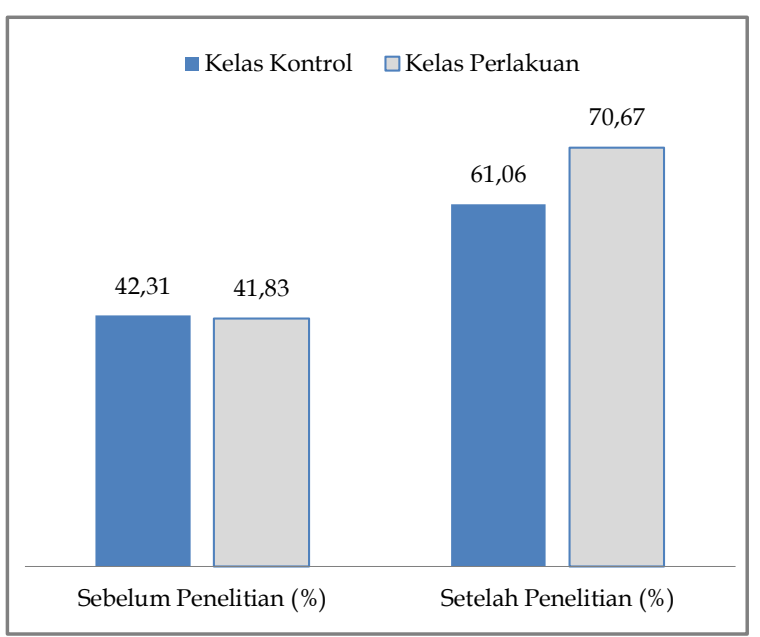

Gambar 2. Grafik Perubahan Motivasi Belajar Siswa

Hal ini menunjukkan bahwa perlakuan yang diterapkan dalam penelitian ini mampu menarik minat siswa untuk belajar IPA.

\section{Analisis Hasil Pembelajaran}

Seiring dengan kemajuan di bidang teknologi informasi dan komunikasi (ICT), maka dunia pendidikan juga telah banyak yang memanfaatkan ICT sebagai media pembelajaran. Penelitian ini juga memanfaatkan ICT untuk mendukung proses pembelajaran, yaitu mengintegrasikan blog dan Facebook dengan model pembelajaran kreatif produktif. Berdasarkan data hasil penelitian diatas, terlihat bahwa tidak terdapat perbedaan signifikan terhadap ratarata hasil belajar siswa kelas VIII yang menggunakan model pembelajaran kreatif produktif terintegrasi dengan blog dan Facebook dengan kelas kontrol.
Prestasi siswa kelas VIII C SMP N 5 Kota Magelang yang merupakan kelas perlakuan, ketuntasan belajar yang dicapai dengan KKM 75 adalah 100\% dengan ratarata pre test 45,92 menjadi 82,50 . Sedangkan untuk kelas VIII A (kelas kontrol), ketuntasan kelas yang dicapai 96,15\%, dengan rata-rata pre test 45,21 menjadi 80,83 . Perbandingan hasil rerata post test kedua kelas tersebut sebesar 1,67. Tetapi hasil uji $\mathrm{t}$ dengan SPSS diperoleh nilai $\mathrm{P}$ (probabilitas) sebesar 0,262 pada taraf signifikansi 5\%. Sehingga disimpulkan bahwa tidak terdapat perbedaan yang signifikan terhadap rata-rata hasil belajar siswa kelas VIII yang menggunakan model pembelajaran kreatif produktif terintegrasi dengan blog dan Facebook dengan kelas kontrol.

Beberapa hasil penelitian juga menunjukan bahwa efektifitas pembelajaran menggunakan ICT cenderung sama bila dibanding dengan pembelajaran konvensional. Tetapi menurut Herman DS., (2008, p.1) keuntungan yang bisa diperoleh adalah dalam hal fleksibilitasnya. Melalui Blog materi pembelajaran dapat diakses kapan saja dan dari mana saja, di samping itu materi juga dapat diperkaya dengan berbagai sumber belajar termasuk multimedia. Media pembelajaran berbasis web dapat dikembangkan dari yang sangat sederhana sampai yang kompleks. Meskipun blog pembelajaran untuk siswa ini hanya dibangun untuk menampilkan kumpulan materi, sementara forum diskusi atau tanya jawab dilakukan bisa dilakukan siswa melalui Facebook. Implementasi dengan cara tersebut terhitung sebagai media pembelajaran berbasis ICT yang paling sederhana.

Berdasarkan hasil wawancara dengan siswa dari kelas perlakuan mereka menyatakan bahwa jika berkomunikasi dengan guru melalui Facebook tidak terbatas hanya di ruang kelas, tetapi bisa dari mana saja. Tugas tidak perlu diprint, tapi cukup dilampirkan saja di Facebook. Siswa juga menyatakan bahwa mereka bisa mengerjakan tugas kelompok secara online tidak perlu meluangkan waktu khusus berkumpul di rumah salah seorang temannya untuk mengerjakan tugas rumah. 
Proses pembelajaran berbasis ICT yang merupakan tuntutan standar proses pembelajaran pada sekolah SSN. Sarana dan prasara yang tersedia di sekolah ini sangat menunjang proses pembelajaran berbasis ICT secara klasikal. Oleh karena itu penenulis berusaha untuk melakukan penelitian ini sebagai alternative solusi yang dianggap dapat memberi pengalaman belajar IPA yang lebih variatif.

Hasil penelitian yang merupakan pengaruh model pembelajaran kreatif produktif yang terintegrasi dengan blog dan Facebook efektif meningkatkan motivasi belajar IPA siswa kelas VIII C SMP N 5 Kota Magelang yaitu dari $41,83 \%$ menjadi $70,76 \%$ setelah proses pembelajaran (termasuk kategori tinggi). Hal ini didukung oleh hasil wawancara kepada siswa bahwa proses pembelajaran menarik, dan siswa lebih fleksibel untuk berkomunikasi dari mana saja dengan guru melalui Facebook dan termotivasi untuk belajar. Sedangkan kelas VIII A (kelas kontrol) motivasi belajar sebelum proses pembelajaran $42,31 \%$ meningkat menjadi $61,06 \%$, termasuk kategori sedang. Sehingga dapat disimpulkan bahwa model pembelajaran kreatif produktif yang terintegrasi dengan blog dan Facebook terdapat perbedaan signifikan terhadap peningkatan motivasi siswa kelas VIII C SMP N 5 Kota Magelang.

\section{Simpulan dan Saran}

Simpulan

Berdasarkan hasil penelitian dan analisis hasil pembelajaran di atas, maka dapat disimpulkan sebagai berikut.

Pertama, proses pembelajaran dengan model pembelajaran kreatif produktif yang terintegrasi dengan blog dan Facebook meningkatkan rata-rata nilai pre test kelas VIII C (kelas perlakuan) dari 45,92 menjadi 82,50 . Ketuntasan yang dicapai dengan KKM 75 adalah 100\%. Sedangkan untuk kelas VIII A (kelas kontrol) hanya meningkatkan rata-rata pre test dari 45,21 menjadi 80,83. Ketuntasan kelas yang dicapai 96,15. Selisih peningkatan rerata pre test kedua kelas tersebut sebesar 1,67.
Tetapi hasil uji $\mathrm{t}$ dengan SPSS diperoleh nilai $\mathrm{P}$ (probabilitas) sebesar 0,262 pada taraf signifikansi 5\%. Sehingga disimpulkan bahwa tidak terdapat perbedaan yang signifikan terhadap rata-rata hasil belajar siswa kelas VIII yang menggunakan model pembelajaran kreatif produktif terintegrasi dengan blog dan Facebook dengan kelas kontrol.

Kedua, model pembelajaran kreatif produktif yang terintegrasi dengan blog dan Facebook efektif meningkatkan motivasi belajar IPA siswa kelas VIII C SMP N 5 Kota Magelang yaitu dari 41,83\% menjadi $70,76 \%$ setelah proses pembelajaran (termasuk kategori tinggi). Hal ini didukung oleh hasil wawancara kepada siswa bahwa proses pembelajaran menarik, dan siswa lebih fleksibel untuk berkomunikasi dari mana saja dengan guru melalui Facebook dan termotivasi untuk belajar. Sedangkan kelas VIII A (kelas kontrol) motivasi belajar sebelum proses pembelajaran $42,31 \%$ meningkat menjadi $61,06 \%$,termasuk kategori sedang. Sehingga dapat disimpulkan bahwa terdapat perbedaan yang signifikan terhadap rata-rata hasil belajar siswa kelas VIII yang menggunakan model pembelajaran kreatif produktif terintegrasi dengan blog dan Facebook dengan kelas kontrol.

Saran

Berdasarkan kesimpulan di atas, penulis berharap bahwa model pembelajaran ini dapat dijadikan alternatif untuk memberikan variasi pengalaman belajar yang bermakna kepada siswa karena terbukti efektif meningkatkan motivasi belajar siswa. Penelitian ini juga diharapkan dapat dijadikan sebagai kajian ilmiah untuk menambah khasanah ilmu pengetahuan bagi guru dan bagi calon guru di Indonesia.

\section{Daftar Pustaka}

Amstrong, Thomas. 2006. Menemukan dan Meningkatkan Kecerdasan Anda Berdasarkan Teori Multiple Intelligence. Jakarta:Gramedia Pustaka Utama. 
Anonim, 2006. Rencana Startegis Departemen Pendidikan Nasional Tahun 20052009. Departemen Pendidikan Nasional. Jakarta.

Arif S. Sadiman,dkk. 2006. Media Pendidikan. Jakarta: Rajawali Pers

Asri Budiningsih, C. 2005. Belajar dan pembelajaran. Jakarta: Rineka Cipta

BSNP. 2006. Panduan Penyusunan KTSP Jenjang Pendidikan Menengah Pertama dan Menengah Atas. Jakarta: BSNP.

Depdiknas. 2006. Kurikulum 2006 standar kompetensi Sekolah Menengah Pertama dan Madrasah Sanawiyah: pedomam khusus mata pelajaran Sains. Jakarta: Penerbit Dharma Bhakti.

Dimyati \& Mudjiono. 2006. Belajar dan pembelajaran. Jakarta: Rineka Cipta

Elida Prayitno. 1989. Motivasi dalam Belajar. Jakarta: Depdikbud.

Herman Dwi Surjono. 2010. Pemanfaatan ICT untuk Meningkatkan Kualitas Pembelajaran. (Makalah seminar "Pembelajaran berbasis ICT"). Yogjakarta: Universitas Negeri Yogyakarta.

Komarudin. 2013. Blog dan Facebook sebagai Media Pembelajaran.diakses tanggal 6 agustus 2013 dari: http://100 papanketik. blogspot.com/2013/04 /blog-dan-Facebook-sebagaimedia.html.

Latuheru, J. D. 1988. Media pembelajaran dalam proses belajar mengajar masa kini. Jakarta: Depdikbud Direktorat Jenderal Pendidikan Tinggi Proyek Pengembangan Lembaga Pendidikan Tenaga Kependidikan.

Mahmudin. 2007. Makalah Pembelajaran Kreatif Produktif. Diakses pada tanggal 20 oktober 2010 dari http://mah muddin.wordpress.com/2007/11/ 09.

Means, B. 1993. Using technology to support education reform. Amerika Serikat: US Government Printing Office.

Miles, Mathew B., and huberman A. Maichel. 1992. Analisis Data Kualitatif: Buku Sumber Tentang Metodemetode Baru (Penerjemah Tjetjep Rohendi Rohidi), jakarta: UI-PRESS.

Moh. Uzer Usman. 1993. Upaya Optimalisasi Kegiatan Belajar Mengajar. Bandung: Rosdakarya.

Mukminan. 2004. Desain pembelajaran. Yogyakarta: Program Pascasarjana Universitas Negeri Yogyakarta.

Mustafa Kamal. 2009. Facebook sebagai media pembelajaran. Diakses tanggal 9 Agustus 2012 dari: http:/ / mustafakamal. biz/2009/04/26/Facebooksebagai-media-pembelajaran.

Solso, Robert, L. 1991. Cognitive psychology. Singapore: Allyn and Bacon.

Sugiyono, Dr. 2010. Metode penelitian Kuantitatif Kualitatif dan $R \mathcal{E} D$, Penerbit Alfabeta

UNESCO. 2002. Information and communication Technologies in Teacher Education. UNESCO: Division of Higher Education.

Udin S. Winataputra, dkk. 2008. Teori Belajar dan Pembelajaran. Jakarta: Universitas Terbuka.

Yusuf Hadimiarso. 2007. Menyemai Benih Teknologi Pendidikan Cet. IV; Jakarta: Kencana.

Zamroni. 2000. Paradigma pendidikan masa depan. Yogyakarta: Bigraf Publishing. 